\title{
The molecular mechanism of vernalization in Arabidopsis and Cereals: Role of Flowering Locus $\mathrm{C}$ and its homologs
}

\author{
Neha Sharma $^{1 *}$, Koen Geuten ${ }^{2}$, Balendu Shekhar Giri ${ }^{3}$, Ajit Varma ${ }^{1}$ \\ ${ }^{1}$ Amity Institute of Microbial Technology, Amity University Uttar Pradesh, India \\ ${ }^{2}$ Department of Biology, KU Leuven, B-3001 Leuven, Belgium \\ ${ }^{3}$ Indian Institute of Technology (IIT-BHU), Varanasi, Uttar Pradesh, India
}

\section{Correspondence \\ * Corresponding author, e-mail: nsharma27@amity.edu}

Winter varieties of plants can flower only after exposure to prolonged cold. This phenomenon is known as vernalization and has been widely studied in the model plant Arabidopsis thaliana as well as in monocots. Through the repression of floral activator genes, vernalization prevents flowering in winter. In Arabidopsis, FLOWERING LOCUS $C$ or FLC is the key repressor during vernalization, while in monocots vernalization is regulated through VRN1, VRN2 and VRN3 (or FLOWERING LOCUS T). Interestingly, VRN genes are not homologous to FLC but FLC homologs are found to have a significant role in vernalization response in cereals. The presence of FLC homologs in monocots opens new dimensions to understand, compare and retrace the evolution of vernalization pathways between monocots and dicots. In this review, we discuss the molecular mechanism of vernalization-induced flowering along with epigenetic regulations in Arabidopsis and temperate cereals. A better understanding of cold-induced flowering will be helpful in crop breeding strategies to modify the vernalization requirement of economically-important temperate cereals.

\section{Introduction}

All living organisms evolve different mechanisms to ensure their survival in local climatic conditions. Being sessile, plants also have evolved different survival mechanisms in response to environmental signals, which allow them to sustain growth in various seasonal changes. Among major environmental

This article has been accepted for publication and undergone full peer review but has not been through the copyediting, typesetting, pagination and proofreading process which may lead to differences between this version and the Version of Record. Please cite this article as doi: $10.1111 / \mathrm{ppl} .13163$ 
signals, temperature and photoperiod are the most crucial in determining flowering time. The majority of the plants growing in temperate climates start flowering only after exposure to prolonged cold, a process known as vernalization (Sheldon et al. 2000, Amasino 2004, Trevaskis et al. 2007, Kim et al. 2009) (Fig. 1). For instance, winter cereals, like wheat and barley, are planted in fall and only flower in spring when winter is passed and photoperiod is inductive.

The process of vernalization was originally described in economically-important temperate cereals (Chouard 1960), as it may have a beneficial effect on crop productivity. Winter varieties of temperate cereals remain in a vegetative state without vernalization and their transition to flowering state only occurs when the vernalization requirement is saturated. Most vernalization-dependent plants are long day (LD) plants and they flower when the day length is inductive (Kim et al. 2009, Wang et al. 2014). A combination of the vernalization requirement and inductive photoperiod prevents the plant from flowering precociously when day length is still short and ensures flowering in favorable conditions during spring when days are long and the temperature is rising.

The vernalization requirement may differ among various plant species and also in different ecotypes within a species. The optimal temperature for vernalization and the acquired length of vernalization vary among different species and accessions of the same species. Generally, the optimal temperature ranges for vernalization response are above or around the freezing point (Wollenberg and Amasino 2012, Duncan et al. 2015, Costa and Dean 2019). This difference in the vernalization requirement helps plants to adapt to the local environmental changes as temperature likely represents a crucial factor (Kim et al. 2009). Varying degrees of the vernalization requirement for different cereal accessions provide a perspective on how plants adapt to different temperatures.

This review focuses on molecular aspects of vernalization-mediated flowering in Arabidopsis thaliana (Arabidopsis) and cereals. Additionally, we discussed the role of FLC in regulating the vernalization response in Arabidopsis and its homologs in temperate cereals. Understanding vernalization in temperate cereals is gaining importance as it could be beneficial in refining breeding efforts of winter varieties of temperate cereals.

\section{Vernalization in Arabidopsis}

Vernalization is well studied in the model plant Arabidopsis. Summer-annual Arabidopsis ecotypes do not need vernalization to flower, while winter-annuals only flower after fulfilling the vernalization 
requirement. In Arabidopsis, two key genes conferred the vernalization requirement: FRIGIDA (FRI) and FLOWERING LOCUS C (FLC) (Lee et al. 1993, Clarke and Dean 1994, Koornneef al. 1994, Whittaker and Dean 2017). FRI encodes a plant-specific scaffold protein and is required for active transcription of FLC (Michaels and Amasino 2001, Jiang et al. 2009). FRI regulates the transcription of FLC through a large protein complex consisting of SUPPRESSOR OF FRI4 (SUF4), FRI-LIKE1 (FRL1) and FRE ESSENTIAL 1 (FES1) (Choi et al. 2011). This protein complex further recruits the transcription activators and chromatin modifying proteins for FLC upregulation (Choi et al. 2011). FLC encodes a MADS-box transcription factor that acts as a repressor of flowering (Michales and Amasino 1999, Sheldon et al. 1999). High levels of FLC represses the expression of floral integrators genes such as FLOWERING LOCUS T (FT), FD and SUPPRESSOR OF OVEREXPRESSION OF CONSTANS1 (SOC1) that results in delayed flowering (Michales et al. 2005, Helliwell et al. 2006, Searle et al. 2006, Deng et al. 2011). FLC binds to the first intron of FT and the promoter of FD and SOC1 (Helliwell et al. 2006, Searle et al. 2006) to perform the repressor function. Expression of FT is induced by the circadian clock coordinated gene CONSTANS $(\mathrm{CO})$ in leaves upon exposure to inductive photoperiods. FT in meristem interacts with $F D$ and promotes SOC1 expression and other floral meristem identity genes like SEPALATA (SEP), FRUITFUL (FUL) and APETALA1 (AP1) to start the transition to flowering state (Turck et al. 2008, Kim et al. 2009). SOC1 is responsible for the activation of another floral meristem identity gene: LEAFY (LFY; Lee et al. 2008; Fig. 2).

In Arabidopsis, repression of FLC is mitotically stable and many genes are involved in stable repression and histone modifications of FLC such as AtVRN1, AtVRN2, VERNALIZATION INSENSITIVE3 (VIN3) and VERNALIZATION5 (VRN5; Levy et al. 2002, Gendall et al. 2001, Wood et al. 2006, Bond et al. 2009, Searle et al. 2006, Greb et al. 2007). AtVRN1 encodes a protein with DNA binding domain and PEST region that are involved in the stable repression of FLC (Levy et al. 2002). AtVRN2 encodes a zinc finger nuclear protein similar to SU(Z)12 in Drosophila and FIS1 and EMF2 in plants (Gendall et al. 2001). AtVRN2 is part of POLYCOMB GROUP REPRESSIVE COMPLEX 2 (PRC2) and plays an important role in stable maintenance of FLC repression after the return to warm conditions (Gendall et al. 2001). VIN3 encodes a chromatin remodeler Plant Homeodomain finger (PHD) protein and is activated by vernalization (Sung and Amasino 2004). Activation of VIN3 results in the repression of FLC by recruiting the PRC2 complex that catalyzed the H3K27me3 modifications of the FLC chromatin (Wood et al. 2006, Bond et al. 2009). VIN3 forms a heterodimer with VRN5 during vernalization and maintains the histone 
modifications necessary for a stable silencing of FLC (Greb et al. 2007, Costa and Dean 2019; Fig. 2). VIN3 acts as a thermosensor component for the epigenetic silencing of FLC and has a key and complex role in influencing the vernalization response in warmer and more variable temperatures (Hepworth et al. 2018). Recent findings in oilseed rape suggested that FLC expression declines predominantly in autumn (specifically around October) rather than winter (O’Neill et al. 2019). Also, FLC levels in autumn can define the vernalization requirements in different climates (Hepworth et al. 2020), suggesting that vernalization is also influenced by autumn and variable temperatures.

\section{Epigenetic regulation of $F L C$ in Arabidopsis}

In Arabidopsis, vernalization mediated repression of FLC is epigenetically regulated through the PRC2 complex (Wood et al. 2006, De Lucia et al. 2008, Angel et al. 2011). The PRC2 complex alters histones at the FLC locus by mediating H3K27me3 and H9K27me3 (trimethylation of histone 3 and 9 on lysine 27 respectively), well established chromatin marks typically associated with a stable epigenetic silencing (Bastow et al. 2004, Sung and Amasino, 2004, Angel et al. 2011). The epigenetic silencing of FLC is quantitatively increased with the duration of cold treatment (Angel et al. 2011, Song et al. 2012, Costa and Dean 2019). This epigenetic state is mitotically stable and resets in every next generation to ensure that the vernalization requirement exists for every progeny or next generation (Sheldon et al. 2008, Choi et al. 2009). In Arabidopsis, there are some mutants in which FLC is downregulated during vernalization but the downregulation is not stably maintained after return to warm conditions. Interestingly, chromatinmodifying proteins were affected in these mutants (Levy et al. 2002, Mylne et al. 2006, Sung et al. 2006), suggesting that stability in the vernalization state is associated with the chromatin modification of target genes.

The setting of the vernalization response via stable FLC repression happens in three phases, i.e. FLC level before cold, cold-mediated repression of FLC and stable silencing after return to warm temperatures. High FLC expression is set during embryogenesis to ensure the vernalization requirement for new progeny (Sheldon et al. 2008, Choi et al. 2009). Before cold, the high FLC expression levels in prevernalized conditions are associated with transcription-activated histone marks. These include di- or trimethylation on Histone 3 at Lysine 4 (H3K4me2 or H3K4me3) and trimethylation on Histone 3 at Lysine 36 (H3K36me3) together with the substitution of Histone 2A (H2A) with H2AZ Histone variant. The initial upregulation of FLC is ensured by RNA polymerase associated factor 1 complex (Paf1 C) and 
FRI (Kim et al. 2009, Song et al. 2012). The Paf1C is an elongation factor which associates with the RNA polymerase II and is required for active elongation (Zhang et al. 2009), while FRI forms a transcription activation complex that ensures high levels of FLC (Choi et al. 2011). Active FRI results in ATWDR5a enrichment at FLC locus and enhances H3K4me3 and H3K36me3 histone marks (Jiang et al. 2009, Pien et al. 2008, Song et al. 2012). Additionally, PRC2 associates with FLC independently of temperatures (De Lucia et al. 2008). In Arabidopsis, the PRC2 complex is constituted of VRN2, SU(Z)12 homolog, SWINGER (SWN), E(z) histone methyltransferase homolog and MSI1 (De Lucia et al. 2008, Song et al. 2012).

Cold-dependent FLC repression resulted in the association of the PRC2 complex and PHD (Plant Homeodomain) to form the PHD-PRC2 complex at the transcription start site (Song et al. 2012, Xiao et al. 2017, Zhou et al. 2018, Costa and Dean 2019). The PHD protein complex consists of three known proteins VIN3, VRN5 and VIN3-LIKE2 (VIL2) (Sung and Amasino, 2004, Wood et al. 2006, De Lucia et al. 2008, Zhu et al. 2015). The activity of the PHD-PRC2 complex results in adding H3K27me3 (transcription repressive histone modification) and removing H3K4me3 (activating histone modification) associated with cold-induced FLC silencing (Fig. 3) (De Lucia et al. 2008, Angel et al. 2011, Song et al. 2012, Whittaker and Dean 2017, Costa and Dean 2019). Moreover, at the beginning of the cold, the expression of the noncoding antisense transcript COOLAIR increases in association with the FLC downregulation (Swiezewski et al. 2009, Song et al. 2012, Costa and Dean 2019, Wu et al. 2020). On the other hand, the sense long noncoding transcript COLDAIR (COLD ASSISTED INTRONIC NONCODING RNA) interacts with PRC2 to mediate FLC silencing (Heo and Sung, 2011, Song et al. 2012) (Fig. 3). It has been shown that the association of VAL1 (Arabidopsis transcriptional repressor) within the nucleation region during vernalization serves as a trigger for PHD-PRC2 silencing at the FLC locus but does not drive the epigenetic silencing (Questa et al. 2016).

When the plants are transferred back to warm conditions after a saturating prolonged cold treatment, the PHD-PRC2 complex spread at the complete FLC locus. This leads to an increase in H3K27me3 histone modifications, which further induces the silencing of the FLC locus (Angel et al. 2011, Song et al. 2012, Questa et al. 2020). The epigenetic silencing of FLC is associated with LIKE HETEROCHROMATIN PROTEIN1 (LHP1) and VRN1 (Mylne et al. 2006). LHP1 likely binds to PRC2 and modifies histones at the FLC locus to maintain stable silencing (Mylne et al. 2006, Kim et al. 2009). Stable silencing of FLC even after vernalization allows plants to flower in spring. However, FLC is reactivated after return to 
warm conditions in perennial Brassicaceae and epigenetic silencing is not stable due to the influence of non-coding SNPs in the nucleation region (Questa et al. 2020).

\section{Vernalization in cereals}

The winter varieties of temperate cereals flower only after saturating the vernalization requirement, while spring varieties flower without vernalization. In winter varieties, vernalization is regulated by two main genes, namely VERNALIZATION1 (VRN1) and VRN2, that further regulate the floral integrator gene VRN3 (Dennis and Peacock, 2009, Greenup et al. 2009, Andres et al. 2012). VRN1 and VRN2 do not resemble Arabidopsis VRN genes suggesting that vernalization pathways may have evolved independently in temperate cereals. VRN1 functions as a floral promoter (Yan et al. 2003, Trevaskis et al. 2003, Shitsukawa et al. 2007, Dixon et al. 2019) and is central to regulating the vernalization response. It encodes a MADS-box transcription factor and is related to the Arabidopsis floral meristem identity genes AP1 (APETALA1) and FUL (Danyluk et al. 2003, Yan et al. 2003, Trevaskis et al. 2003, Preston and Kellogg 2006). In winter varieties of wheat and barley, VRN1 expression is induced by cold exposure (Yan et al. 2003, Trevaskis et al. 2003). However, in spring varieties, VRN1 is still expressed even in absence of cold exposure, which reduces or even abolishes their need for vernalization (Trevaskis et al. 2003, Yan et al. 2003). Similarly to Arabidopsis in which FLC downregulation is epigeneticallyregulated, VRN1 upregulation is also epigenetically-regulated. VRN1 upregulation is associated with the inhibition of H3K27me3 (repressive chromatin marks) and the induction of the H3K4me3 level (active chromatin marks; Oliver et al. 2009). VRN1 promoter region and first intron play a crucial role in maintaining the vernalization response (Yan et al. 2004, Fu et al. 2005). Deletions in the promoter region and first intron of VRN1 are correlated in spring wheat varieties (Fu et al. 2005, Muterko et al. 2016, Xu et al. 2018). The consecutive upregulation of VRN1 leads to the low expression of the floral repressor VRN2 after prolonged cold (Distelfeld et al. 2009, Hemming et al. 2008, Trevaskis et al. 2006, Jarillo and Pineiro. 2011). However, it has been also reported that VRN1 expression is not mandatory for flowering, or the downregulation of VRN2 during cold, indicating the possibility that additional genes can be involved in VRN2 downregulation upon vernalization (Chen and Dubcovsky 2012). VRN2 encodes a zincfinger CCT domain protein and there is no homolog found in Arabidopsis (Yan et al. 2004). CCT domain is important for regulating the vernalization requirement and mutations in the CCT domain result in the elimination of vernalization requirement (Distelfeld et al. 2009, Dubcovsky et al. 2005, Li et al. 2017). In 
wheat and barley, long days in autumn induced VRN2 that further represses VRN3 to inhibit flowering (Distelfeld and Dubcovsky 2010, Chen and Dubcovsky 2012). The expression of VRN1 is regulated by vernalization and independent from photoperiod, contrary to VRN2 expression that is regulated by photoperiod (Trevaskis et al. 2006, Dubcovsky et al. 2006, Woods et al. 2016, Monteagudo et al. 2019) suggesting that photoperiod also has a significant role in vernalization-induced flowering in cereals. In wheat and barley, the regulation of VRN1 at higher ambient temperatures controls the spikelet number, floret number and flowering time (Ejaz and Von Korff. 2017, Dixon et al. 2019). Finally, the downregulation of VRN2 releases VRN3. VRN3 is a homolog of FT (Yan et al. 2004), which induces flowering after vernalization and in response to optimal photoperiod (Distelfeld et al. 2009, Trevaskis et al. 2007, Turner et al. 2005, Yan et al. 2006) (Fig. 4). The floral promoter activity of VRN3 is activated by long days, similar to FT in Arabidopsis (Yan et al. 2006). VRN3 stimulates the expression of VRN1 in leaves by a positive feedback loop. VRN3 increases VRN1 expression through communicating with another transcription factor (FDL2) that binds to the VRN1 promoter (Li et al. 2008).

Brachypodium distachyon, a temperate grass model system, also exhibit similar vernalization mechanism like wheat and barley (Higgins et al. 2010, Ream et al. 2012). VRN1 expression is increased upon cold exposure and remains high even after vernalization (Ream et al. 2014, Woods et al. 2016). The high expression level of $V R N 1$ and $V R N 3$ after cold induces the transition from vegetative to reproductive state. Recently, it has been shown that inhibition of VRN1 expression before cold is mediated through REPRESSOR OF VERNALIZATION1 (RVR1), a gene upstream to VRN1 that has a role in establishing vernalization requirement (Woods et al. 2017b). Interestingly, VRN2 functions as a floral repressor in Brachypodium but, differently from wheat and barley, VRN2 is not downregulated by cold through VRN1 (Ream et al. 2014, Woods et al. 2016, Xu et al. 2018). This suggests that the functions of VRN1 and VRN2 as activator and repressor of flowering, respectively, remain conserved even after the diversification of temperate grasses but VRN1 and VRN2 regulatory loop do not seem to be conserved across Pooideae (Woods et al. 2016, Woods et al., 2017a). In short day photoperiod, vernalization response is regulated by FT/VRN3 paralog FT-like9 (FTL9) to confer competency for floral transition (Woods et al., 2019).

\section{Epigenetic regulation of VRN1 in temperate cereals}


Similarly to Arabidopsis, the regulation of vernalization response is epigenetically-regulated in temperate grasses. In wheat and barley, vernalization induced epigenetic modifications of the floral promoter VRN1. The expression of VRN1 is induced by low temperatures and remains high even after return to warm conditions. Epigenetic modifications in VRN1 promoter and the first intron are responsible for winter memory in wheat and barley (Fu et al. 2005, Oliver et al. 2009, Diallo et al. 2012). Before cold, H3K27me3 repressive histone marks accumulate at the VRN1 locus and result in the low expression level of VRN1 (Oliver et al. 2009). During cold, H3K27me3 levels decrease while the active histone marks H3K4me3 and H3K36me3 increased at the VRN1 chromatin (Fu et al. 2005, Xiao et al. 2014, Oliver et al. 2009, Diallo et al. 2012, Woods et al., 2017b). These histone marks are maintained even after return to warm conditions. H3K27me3 and H3K4me3 histone marks are maintained by the Polycomb and trithorax group complexes (Chittock et al. 2017). In Brachypodium, the CURLY LEAF orthologue ENHANCER OF ZESTE like-1 (EZL1) is required for the deposition of H3K27me3 at VRN1 before cold (Lomax et al. 2018). This reduction in H3K27me3 and enrichment of H3K4me3 at VRN1 is associated with the stable expression of VRN1 during vernalization (Distelfeld et al. 2010, Woods et al. 2014, Woods et al. 2017b). In Brachypodium, VRN3 is also epigenetically-regulated during vernalization and exhibits an alteration in H3K27me3 and H3K4me3 histone marks similar to VRN1 (Huan et al. 2018). Hence, the winter memory of temperate cereals is maintained through the stable epigenetic regulation of VRN1 but detailed mechanism on how plants sense cold still need to be explored.

\section{FLC homologs in cereals}

In monocots such as wheat and barley, VERNALIZATION genes (VRN1, VRN2 and VRN3) are important regulators of the vernalization-mediated flowering. In Arabidopsis, FRI-FLC are key genes in maintaining the vernalization response. As discussed above, the mechanisms of vernalization and epigenetic regulation of FLC and VRN1 are also different between monocots and eudicots. However, the identification of FLC orthologs in monocots, through a combination of phylogenetic reconstructions and genomic synteny, provided a new dimension to understand the vernalization pathway (Ruelens et al. 2013). In temperate cereals, there are three FLC homologous genes: ODDSOC2, ODDSOC1 and MADS37. MADS-box genes, ODDSOC1 and ODDSOC2 belong to OsMADS51-like genes, from which several members had already been shown to be vernalization responsive, including the two paralogs 
HvODDSOC1 and HvODDSOC2 from barley (Hordeum vulgare) (Greenup et al. 2010, Monteagudo et al. 2019), while MADS37 belongs to OsMADS37-like genes (Ruelens et al. 2013).

In Brachypodium, ODDSOC2 and MADS37 are responsive to cold while the expression of ODDSOC1 remains unchanged in response to vernalization in Bd-21, a spring Brachypodium accession (Ruelens et al. 2013). Similar to FLC in Arabidopsis, the expression of ODDSOC2 is high before vernalization and low during and after vernalization in Brachypodium accessions (Ruelens et al. 2013, Sharma et al. 2017). In barley, the expression of an FLC orthologue, ODDSOC2, is also downregulated during vernalization and reported to be functional in vernalization response (Greenup et al. 2010). ODDSOC2 acts as a floral repressor during vernalization (Greenup et al. 2008, Hemming et al. 2012). ODDSCO2-overexpressing plants flower late, together with a reduced spike growth, stem and leaf lengths (Greenup et al. 2010). In barley, VRN1 downregulated the expression of ODDSOC2 by binding to its promoter and inhibit the expression of FPF1-like genes to prevent flowering (Deng et al. 2015, Greenup et al. 2010) (Fig. 4). Recently, it has been shown that ODDSOC2 ( $\mathrm{HvOS2}$ ) appears to have a potential role in regulating vernalization-mediated flowering in barley (Montengudo et al. 2019).

In wheat, four genes were identified as FLC homologs: TaAGL41, TaAGL33, TaAGL22 and TaMADS2 (Zhao et al. 2006, Ruelens et al. 2013, Sharma et al. 2017). FLC homologs, TaAGL33 and TaAGL22 are MADS-box transcripts that exhibit the most similar expression than FLC during vernalization and are stably downregulated by vernalization in a diverse set of wheat varieties (Sharma et al. 2017). Similar to FLC in Arabidopsis, winter wheat varieties have high a expression level of TaAGL33 and TaAGL22, while their expression levels are low in spring wheat varieties before cold exposure (Sharma et al. 2017, Winfeild et al. 2009; Table 1). The expression of ODDOSC2 in short days is regulated by temperature and is independent from photoperiod, while VRN2 expression is dependent on photoperiod suggesting that the repressor activity during vernalization is combinedly maintained by ODDOC2 and VRN2 (Hemming et al. 2012, Dixon et al. 2019). These results from Brachypodium, barley and wheat indicate that the evolution of vernalization pathways seems to be related to some extent between monocots and eudicots.

\section{FLC homologs can be a good predictor of vernalization}

Winter varieties of different plant species have a wide variation in vernalization requirements that helps plants to survive to local climatic conditions and to flower at the optimal time (Kim et al. 2009, Ream et 
al. 2013, Hepworth et al. 2015, Bloomer and Dean 2017, Bouche et al. 2017). In Arabidopsis, allelic differences at the FLC and FRIGIDA (FRI) locus define the natural variation in vernalization (Clarke and Dean 1994, Shindo et al. 2005, Bloomer et al. 2017, Whittaker \& Dean 2017). The early flowering phenotype of spring Arabidopsis ecotypes is found to be associated with the loss of function mutations at the FLC locus. In temperate grasses like Brachypodium, ODDSOC2 expression before cold can predict the vernalization requirement (Sharma et al. 2017), suggesting that ODDSOC2 could function as a potential indicator to define the natural variations of vernalization response. Winter barley and Brachypodium accessions have high expression levels of ODDSOC2, while expression is low in spring accessions before vernalization (Greenup et al. 2010, Sharma et al. 2017). In winter wheat varieties, allelic variations at VRN1 are associated with the important determinant for the vernalization requirement (Golovina et al. 2010, Konopatskaia et al. 2016). However, high ODDSOC2 levels in winter wheat varieties and low ODDSOC2 levels in spring wheat varieties prior to cold exposure suggested that ODDSOC2 may also have a potential role in defining the vernalization response in wheat varieties (Sharma et al. 2017).

\section{Conclusion and future perspective}

Arabidopsis and temperate cereals are two main systems in which the molecular mechanisms of vernalization have been studied. In both systems, vernalization results in the induction of regulatory genes. In Arabidopsis, cold represses FLC that serves as the central regulator while in temperate cereals cold induces VRN1 expression and initiates the vernalization mechanism. The vernalization pathways in monocots and eudicots are regulated through a completely different set of genes and they are thought to have evolved independently. However, the presence of FLC homologs and the functional conservation of ODDSOC2 in temperate cereals indicate that the evolution of the vernalization pathways is not fully independent.

The fundamental question of the cold sensing mechanism of vernalization still needs to be explored. Vernalization-induced epigenetic modifications at VRN1 and ODDSOC2 could provide the key inputs for exploring cold-sensing mechanism in temperate cereals. The current state of research in this domain is generating new questions and promising future findings could be beneficial in breeding efforts to refine vernalization-induced flowering in cereals and to adapt winter crops to a possible changing environment. 


\section{Author contributions}

The manuscript is written by N.S. All authors edited and finalized the manuscript.

\section{Data availability statement}

Data sharing is not applicable to this article as no new data were created or analyzed in this study

\section{References}

Amasino R (2004) Vernalization, competence, and the epigenetic memory of winter. Plant Cell 16: 25532559

Andres F, Coupland G (2012).The genetic basis of flowering responses to seasonal cues. Nat Rev Genet 13: 627-639

Angel A, Song J, Dean C, Howard M (2011) A Polycomb-based switch underlying quantitative epigenetic memory. Nature 476: 105-108

Bastow R, Mylne JS, Lister C, Lippman Z, Martienssen RA, Dean C (2004) Vernalization requires epigenetic silencing of FLC by histone methylation. Nature 427: 164-167

Bloomer RH, Dean C (2017) Fine-tuning timing: natural variation informs the mechanistic basis of the switch to flowering in Arabidopsis thaliana. Journal of Experimental Botany 68: 5439-5452

Bond DM, Dennis ES, Finnegan EJ (2009) Hypoxia: a novel function for VIN3. Plant Signal Behav 4: 773-776

Bouché F, Woods DP, Amasino RM (2017) Winter memory throughout the plant kingdom: different paths to flowering. Plant Physiology 173: 27-35

Chen A, Dubcovsky J (2012) Wheat TILLING mutants show that the vernalization gene VRN1 downregulates the flowering repressor VRN2 in leaves but is not essential for flowering. PLoS Genet 8: e1003134

Chittock EC, Latwiel S, Miller T, Mueller CW (2017) Molecular architecture of polycomb repressive complexes. Biochem. Soc. T 45: 193-205

Choi J, Hyun Y, Kang MJ, In Yun H, Yun JY, Lister C, Dean C, Amasino RM, Noh B, Noh YS, Choi Y (2009) Resetting and regulation of Flowering Locus C expression during Arabidopsis reproductive development. Plant J 57: 918-931 
Choi K, Kim J, Hwang HJ, Kim S, Park C, Kim SY, Lee I (2011) The FRIGIDA complex activates transcription of $F L C$, a strong flowering repressor in Arabidopsis, by recruiting chromatin modification factors. The Plant Cell 23: 289-303

Chouard P (1960) Vernalization and Its Relations to Dormancy. Annual Review of Plant Physiology and Plant Molecular Biology 11: 191-238

Clarke JH, Dean C (1994) Mapping FRI, a locus controlling flowering time and vernalization response in Arabidopsis thaliana. Molecular and General Genetics 242: 81-89

Costa S, Dean C (2019) Storing memories: the distinct phases of Polycomb-mediated silencing of Arabidopsis FLC. Biochemical Society Transactions 47: 1187-1196

Danyluk J, Kane NA, Breton G, Limin AE, Fowler DB, Sarhan F (2003) TaVRT-1, a putative transcription factor associated with vegetative to reproductive transition in cereals. Plant Physiol. 132: 1849-1860

De Lucia F, Crevillen P, Jones AM, Greb T, Dean C (2008) A PHD-polycomb repressive complex 2 triggers the epigenetic silencing of FLC during vernalization. Proc Natl Acad Sci USA 105: 16831-16836 Deng W, Casao MC, Wang P , Sato K, Hayes PM, Finnegan E J, Trevaskis B (2015) Direct links between the vernalization response and other key traits of cereal crops. Nat Commun 6: 5882

Deng W, Ying H, Helliwell CA, Taylor JM, Peacock WJ, Dennis ES (2011) FLOWERING LOCUS C (FLC) regulates development pathways throughout the life cycle of Arabidopsis. Proc. Natl Acad. Sci. USA 108: 6680-6685

Dennis ES, Peacock WJ (2009) Vernalization in cereals. J Biol 8: 57

Diallo AO, Ali-Benali MA, Badawi M, Houde M, Sarhan F (2012) Expression of vernalization responsive genes in wheat is associated with histone H3 trimethylation. Mol. Genet. Genomics 287: 575590

Distelfeld A, Dubcovsky J (2010) Characterization of the maintained vegetative phase deletions from diploid wheat and their effect on VRN2 and FT transcript levels. Mol. Genet. Genomics 283: 223-232

Distelfeld A, Li C, Dubcovsky J (2009) Regulation of flowering in temperate cereals. Curr Opin Plant Biol 12: 178-184

Dixon LE, Karsai I, Kiss T, Adamski NM, Liu Z, Ding Y, et al. (2019) VERNALIZATION1 controls developmental responses of winter wheat under high ambient temperatures. Development 146: $\operatorname{dev} 172684$ 
Dubcovsky J (2005) Regulation of flowering time in wheat and barley. Comp Biochem Phys 141: 263264

Dubcovsky J, Loukoianov A, Fu D, Valarik M, Sanchez A, Yan L (2006) Effect of photoperiod on the regulation of wheat vernalization genes VRN1 and VRN2. Plant Mol. Biol. 60: 469-480

Duncan S, Holm S, Questa J, Irwin J, Grant A, Dean C (2015) Seasonal shift in timing of vernalization as an adaptation to extreme winter. Elife 4: e06620

Ejaz M, VonKorff M (2017) The genetic control of reproductive development under high ambient temperature. Plant Physiol 173: 294-306

Fu DL, Szucs P, Yan L, Helguera M, Skinner JS, von Zitzewitz J, Hayes PM, Dubcovsky J (2005) Large deletions within the first intron in VRN-1 are associated with spring growth habit in barley and wheat. Mol. Genet Genomics 273: 54-65

Gazzani S, Gendall AR, Lister C, Dean C (2003) Analysis of the molecular basis of flowering time variation in Arabidopsis accessions. Plant Physiol 132: 1107-1114

Gendall AR, Levy YY, Wilson A, Dean C (2001) The VERNALIZATION 2 gene mediates the epigenetic regulation of vernalization in Arabidopsis. Cell 107: 525-535

Greb, T, Mylne JS, Crevillen P, Geraldo N, An H, Gendall AR, Dean C (2007) The PHD finger protein VRN5 functions in the epigenetic silencing of Arabidopsis FLC. Curr Biol 17: 73-78

Greenup A, Peacock WJ, Dennis ES, Trevaskis B (2009) The molecular biology of seasonal floweringresponses in Arabidopsis and the cereals. Ann Bot 103: 1165-1172

Greenup AG, Sasani S, Oliver SN, Talbot MJ, Dennis ES, Hemming MN, Trevaskis B (2010) ODDSOC2 is a MADS box floral repressor that is down-regulated by vernalization in temperate cereals. Plant Physiol 153: $1062-1073$

Helliwell CA, Wood CC, Roberston M, Peacock JW, Dennis ES (2006) The Arabidopsis FLC protein interacts directly in vivo with SOC1 and FT chromatin and is part of a high-molecular-weight protein complex. Plant J 46: 183-192

Hemming MN, Peacock WJ, Dennis ES, Trevaskis B (2008) Low-temperature and daylength cues are integrated to regulate FLOWERING LOCUS T in barley. Plant Physiol 147: 355-366

Hemming MN, Walford SA, Fieg S, Dennis ES, Trevaskis B (2012) Identification of High-TemperatureResponsive Genes in Cereals. Plant Physiology 158: 1439-1450 
Heo JB, Sung S (2011) Vernalization-mediated epigenetic silencing by a long intronic noncoding RNA. Science 331: 76-79

Hepworth J, Antoniou-Kourounioti RL, Berggren K, Selga C, Tudor E, Yates B, Cox D, Harris BRC, Irwin J, Howard M, Säll T, Holm S, Dean C (2020) Natural variation in autumn FLC levels, rather than epigenetic 2 silencing, aligns vernalization to different climates. BioRxiv doi: doi.org/10.1101/2020.04.19.049148

Hepworth J, Antoniou-Kourounioti RL, Bloomer RH, Selga C, Berggren K, Cox D, Harris BRC, Irwin JA, Holm S, Sall T, Howard M, Dean C (2018) Absence of warmth permits epigenetic memory of winter in Arabidopsis. Nat. Commun. 9: 639

Hepworth J, Dean C (2015) Flowering Locus C’s lessons: conserved chromatin switches underpinning developmental timing and adaptation. Plant Physiol 168: 1237-1245

Higgins JA, Bailey PC, Laurie DA (2010) Comparative genomics of flowering time pathways using Brachypodium distachyon as a model for the temperate grasses. PLoS ONE 5: e10065

Huan Q, Mao Z, Chong K, Zhang J (2018) Global analysis of H3K4me3/ H3K27me3 in Brachypodium distachyon reveals VRN3 as critical epigenetic regulation point in vernalization and provides insights into epigenetic memory. New Phytol. 219: 1373-1387

Jarrillo JA, Pineiro M (2011) Timing is everything in plant development. The central role of floral repressors. Plant Sci 181: 364-378

Jiang, D, Gu X, He Y (2009) Establishment of the winter-annual growth habit via FRIGIDA - mediated histone methylation at FLOWERING LOCUS C in Arabidopsis. Plant Cell, 21: 1733-1746

Jianng D, Gu X, He Y (2009) Establishment of the winter-annual growth habit via FRIGIDA-mediated histone methylation at FLOWERING LOCUS C in Arabidopsis. Plant Cell 21: 1733-1746

Kim DH, Doyle MR, Sing S, Amasino RM (2009) Vernalization: winter and the timing of flowering in plants. Annu Rev Cell Dev Biol 25: 277-299

Koornneef M, Vries BH, Hanhart C, Soppe W, Peeters T (1994) The phenotype of some late-flowering mutants is enhanced by a locus on chromosome 5 that is not effective in the Landsberg erecta wildtype. The Plant Journal 6: 911-919

Lee I, Bleecker A, Amasino R (1993) Analysis of naturally occurring late flowering in Arabidopsis thaliana. Molecular and General Genetics 237: 171-176 
Lee J, Oh M, Park H, Lee I (2008) SOC1 translocated to the nucleus by interaction with AGL24 directly regulates leafy. Plant J 55: 832-843

Levy YY, Mesnage S, Mylne JS, Gendall AR, Dean C (2002) Multiple roles of Arabidopsis VRN1 in vernalization and flowering time control. Science 297: 243-246

Li C, Dubcovsky J (2008) Wheat FT protein regulates VRN1 transcription through interactions with FDL2. Plant J. 55: 543-554

Li Y, Xu M (2017) CCT family genes in cereal crops: A current overview. Crop J 5: 449-458

Lomax A, Woods DP, Dong Y, Bouche F, Rong Y, Mayer KS, Zhong X, Amasino RM (2018) An ortholog of CURLY LEAF/ENHANCER OF ZESTE like-1 is required for proper flowering in Brachypodium distachyon. The Plant Journal : For Cell and Molecular Biology 93: 871-882

Michaels SD, Amasino RM (1999) FLOWERING LOCUS C encodes a novel MADS domain protein that acts as a repressor of flowering. Plant Cell 11: 949-956

Michaels SD, Amasino RM (2001) Loss of FLOWERING LOCUS C activity eliminates the lateflowering phenotype of FRIGIDA and autonomous pathway mutations but not responsiveness to vernalization. Plant Cell 13: 935-941

Michaels SD, He Y, Scortecci KC, Amasino RM (2003) Attenuation of FLOWERING LOCUS C activity as a mechanism for the evolution of summer-annual flowering behavior in Arabidopsis. Proc Natl Acad Sci U S A 100: 10102-10107

Michaels SD, Himelblau E, Kim SY, Schomburg FM, Amasino RM (2005) Integration of flowering signals in winter-annual Arabidopsis. Plant Physiol 137: 149-156

Monteagudo A, Igartua E, Contreras-Moreira B, Gracia MP, Ramos J, Karsai I, Casas AM (2019) Finetuning of the flowering time control in winter barley: the importance of HvOS2 and HvVRN2 in noninductive conditions. BMC Plant Biol 19: 113

Muterko A, Kalendar R, Salina E (2016) Novel alleles of the VERNALIZATION1 genes in wheat are associated with modulation of DNA curvature and flexibility in the promoter region. BMC Plant Biol 16: 9

Mylne JS, Barrett L, Tessadori F, Mesnage S, Johnson L, Bernatavichute YV, Jacobsen SE, Fransz P, Dean C (2006) LHP1, the Arabidopsis homologue of HETEROCHROMATIN PROTEIN1, is required for epigenetic silencing of FLC. Proc Natl Acad Sci U S A 103: 5012-5017 
O’Neill CM, Lu X, Calderwood A, Tudor EH, Robinson P, Wells R, Morris R, Penfield S (2019) Vernalization and floral transition in autumn drive winter annual life history in oilseed rape. Curr. Biol. 29: $4300-4306$

Oliver SN, Finnegan EJ, Dennis ES, Peacock WJ, Trevaskis B (2009) Vernalization-induced flowering in cereals is associated with changes in histone methylation at the VERNALIZATION1 gene. Proc Natl Acad Sci U S A, 106: 8386-8391

Pien S, Fleury D, Mylne JS, Crevillen P, Inzé D, Avramova Z, Dean C, Grossniklaus U (2008) ARABIDOPSIS TRITHORAX1 dynamically regulates FLOWERING LOCUS C activation via histone 3 lysine 4 trimethylation. Plant Cell 20: 580-588

Preston JC, Kellogg EA (2006) Reconstructing the evolutionary history of paralogous APETALA1/FRUITFULL-like genes in grasses (Poaceae). Genetics 174: 421-437

Questa J, Song J, Geraldo N, An H, Dean C (2016) Arabidopsis transcriptional repressor VAL1 triggers Polycomb silencing at FLC during vernalization. Science 353: 485-488

Qüesta JI, Antoniou-Kourounioti RL, Rosa S, Li P, Duncan S, Whittaker C, Howard M, Dean C (2020) Noncoding SNPs influence a distinct phase of Polycomb silencing to destabilize long-term epigenetic memory at Arabidopsis FLC. Genes Dev 34: 446-461

Ream TS, Woods DP, Schwartz CJ, Sanabria CP, Mahoy JA, Walters EM, Kaeppler HF, Amasino RM (2014) Interaction of photoperiod and vernalization determines flowering time of Brachypodium distachyon. Plant Physiol 164: 694-709

Ream TS, Woods DP, Amasino RM (2012) The molecular basis of vernalization in different plant groups. Cold Spring Harb. Symp. Quant Biol 77: 105-115

Ruelens P, De Maagd RA, Proost S, Theissen G, Geuten K, Kaufmann K (2013) FLOWERING LOCUS $\mathrm{C}$ in monocots and the tandem origin of angiosperm-specific MADS-box genes. Nat Commun 4: 2280

Searle I, He Y, Turck F, Vincent C, Fornara F, Krober S, Amasino RA, Coupland G (2006) The transcription factor FLC confers a flowering response to vernalization by repressing meristem competence and systemic signaling in Arabidopsis. Genes Dev 20: 898-912

Sharma N, Ruelens P, D’Hauw M, Maggen T, Dochy N, Torfs S, Kaufmann K, Geuten K (2017) A Flowering Locus $\mathrm{C}$ homolog is a vernalization-regulated repressor in Brachypodium and is cold regulated in wheat. Plant Physiology 173: 1301-1315 
Sheldon CC, Burn JE, Perez PP, Metzger J, Edwards JA, et al. (1999) The FLF MADS box gene: a repressor of flowering in Arabidopsis regulated by vernalization and methylation. Plant Cell 11: 445-458 Sheldon CC, Hills MJ, Lister C, Dean C, Dennis ES, Peacock WJ (2008) Resetting of FLOWERING LOCUS C expression after epigenetic repression by vernalization. Proc Natl Acad Sci U S A 105: 22142219

Sheldon CC, Rouse DT, Finnegan EJ, Peacock WJ, Dennis ES (2000) The molecular basis of vernalization: the central role of FLOWERING LOCUS C (FLC). PNAS 97: 3753-3758

Shindo C, Aranzana MJ, Lister C, Baxter C, Nicholls C, Nordborg M, Dean C (2005) Role of FRIGIDA and FLOWERING LOCUS C in Determining Variation in Flowering Time of Arabidopsis. Plant Physiol 138: $1163-1173$

Shitsukawa N, Ikari C, Shimada S, Kitagawa S, Sakamoto K, et al. (2007). The einkorn wheat (Triticum monococcum) mutant, maintained vegetative phase, is caused by a deletion in the VRN1 gene. Genes Genet Syst 82: 167-170

Song J, Angel A, Howard M, Dean C (2012) Vernalization - a cold-induced epigenetic switch. J Cell Sci 125: 3723-3731

Sung S, Amasino RM (2004) Vernalization and epigenetics: how plants remember winter. Curr Opin Plant Biol 7: 4-10

Sung S, He Y, Eshoo TW, Tamada Y, Johnson L, Nakahigashi K, Goto K, Jacobsen SE, Amasino RM (2006) Epigenetic maintenance of the vernalized state in Arabidopsis thaliana requires LIKE HETEROCHROMATIN PROTEIN 1. Nature Genetics 38: 706-710

Swiezewski S, Liu F, Magusin A, Dean C (2009) Cold-induced silencing by long antisense transcripts of an Arabidopsis Polycomb target. Nature 462: 799-802

Trevaskis B, Bagnall DJ, Ellis MH, Peacock WJ, Dennis E (2003) MADS box genes control vernalization-induced flowering in cereals. Proc Natl Acad Sci U S A 100: 13099-13104

Trevaskis B, Hemming MN, Dennis ES, Peacock WJ (2007) The molecular basis of vernalizationinduced flowering in cereals. Trends Plant Sci 12: 352-357

Trevaskis B, Hemming MN, Peacock WJ, Dennis ES (2006) HvVRN2 responds to daylength, whereas HvVRN1 is regulated by vernalization and developmental status. Plant Physiol 140: 1397-1405

Turck F, Fornara F, Coupland G (2008) Regulation and identity of florigen: FLOWERING LOCUS T moves center stage. Annu Rev Plant Biol 59: 573-594 
Turner A, Beales J, Faure S, Dunford RP, Laurie DA (2005) The pseudo-response regulator Ppd-H1 provides adaptation to photoperiod in barley. Science 310: 1031-1034

Wang Y, Gu X, Yuan W, Schmitz RJ, He Y (2014) Photoperiodic control of the floral transition through a distinct polycomb repressive complex. Dev Cell 28: 727-736

Whittaker C, Dean C (2017) The FLC locus: a platform for discoveries in epigenetics and adaptation. Annual Review of Cell and Developmental Biology 33: 555-575

Winfield MO, Lu C, Wilson ID, Coghill JA, Edwards KJ (2009) Cold and light-induced changes in the transcriptome of wheat leading tophase transition from vegetative to reproductive growth. BMC Plant Biol 9: 55

Wollenberg AC, Amasino RM (2012) Natural variation in the temperature range permissive for vernalization in accessions of Arabidopsis thaliana. Plant, Cell and Environment 35: 2181-2191

Wood CC, Robertson M, Tanner G, Peacock WJ, Dennis ES, Helliwell CA (2006) The Arabidopsis thaliana vernalization response requires a polycomb-like protein complex that also includes VERNALIZATION INSENSITIVE 3. Proc Natl Acad Sci U S A 103: 14631-14636

Woods D, Dong Y, Bouche F, Bednarek R, Rowe M, Ream T, Amasino R (2019) A florigen paralog is required for short-day vernalization in a pooid grass. eLife 8: e42153

Woods DP, Bednarek R, Bouche' F, Gordon SP, Vogel JP, Garvin DF, Amasino RM (2017a) Genetic architecture of flowering-time variation in Brachypodium distachyon. Plant Physiol 173: 269-279

Woods DP, McKeown MA, Dong Y, Preston JC, Amasino RM (2016) Evolution of VRN2/Ghd7-like genes in vernalization mediated repression of grass flowering. Plant Physiol 170: 2124-2135

Woods DP, Ream TS, Bouche F, Lee J, Thrower N, Wilkerson C, Amasino RM. (2017b) Establishment of a vernalization requirement in Brachypodium distachyon requires repressor of vernalization1. PNAS 114: 6623-6628

Wu Z, Fang X, Zhu D, Dean C (2020) Autonomous Pathway: FLOWERING LOCUS C Repression through an Antisense-Mediated Chromatin-Silencing Mechanism. Plant Physiol. 182: 27-37

Xiao J, Xiao J, Jin R, Yu X, Shen M, Wagner JD, et al (2017) Cis and trans determinants of epigenetic silencing by Polycomb repressive complex 2 in Arabidopsis. Nat Genet 49: 1546-1552

Xiao J, Xu S, Li C, Xu Y, Xing L, Niu Y, Huan Q, Tang Y, Zhao C, Wagner D, Gao C, Chong K (2014) O-GlcNAc-mediated interaction between VER2 and TaGRP2 elicits TaVRN1 mRNA accumulation during vernalization in winter wheat. Nat. Commun. 5: 4572 
Xu S, Chong K. (2018). Remembering winter through vernalisation. Nat. Plants 4: 997-1009

Yan L, Fu D, Li C, Blechl A, Tranquilli G, Bonafede M, Sanchez A, Valarik M, Yasuda S, Dubcovsky J (2006) The wheat and barley vernalization gene VRN3 is an orthologue of FT. Proc Natl Acad Sci U S A 103: 19581-19586

Yan L, Loukoianov A, Blechl A, Tranquilli G, Ramakrishna W, et al. (2004). The wheat VRN2 gene is a flowering repressor down-regulated by vernalization. Science 303: 1640-44

Yan L, Loukoianov A, Tranquilli G, Helguera M, Fahima T, Dubcovsky J (2003) Positional cloning of the wheat vernalization gene VRN1. Proceedings of the National Academy of Sciences of the U S A 100: 6263-6268

Zhang Y, Sikes ML, Beyer AL, Schnneider DA (2009) The Paf1 complex is required for efficient transcription elongation by RNA polymerase I. Proc Natl Acad Sci U S A 106: 2153-2158

Zhao T, Ni Z, Dai Y, Yao Y, Nie X, Sun Q (2006) Characterization and expression of 42 MADS-box genes in wheat (Triticum aestivum L.). Mol Genet Genomics 276: 334-350

Zhou Y, Wang Y, Krause K, Yang T, Dongus JA, Zhang Y, Turck F (2018) Telobox motifs recruit CLF/SWN-PRC2 for H3K27me3 deposition via TRB factors in Arabidopsis. Nat Genet 50: 638-644

Zhu D, Rosa S, Dean C (2015) Nuclear organization changes and the epigenetic silencing of FLC during vernalization. J Mol Biol 427: 659-669

\section{Figure legends:}

Fig. 1. Molecular mechanisms of vernalization-mediated flowering: In Arabidopsis, FLC expression? is high before cold (autumn). During winter, prolonged cold exposure results in low FLC level and represses FT. Later in spring, long days induce FT expression and accelerate flowering. In temperate cereals, VRN2 represses FT before cold. In winter, cold-exposure induced the expression of VRN1 and represses VRN2. $V R N 1$ remains high in spring and allows the induction of $V R N 3$ to promote flowering.

Fig. 2. Vernalization-induced flowering mechanisms in Arabidopsis: Flowering Locus C (FLC) is the key repressor of flowering. FLC is repressed by prolonged cold exposure results in the downregulation of floral integrators genes such as FT, FD and SOC1 that promotes flowering. FT is induced by $C O$ and photoperiod pathway. FT together with FD is meristem activates the expression of SOC1 and floral 
meristem identity genes like FUL and $A P 1$ and accelerate flowering. Gibberellin promotes flowering by inducing SOC1 and LFY.

Fig. 3. Epigenetic modifications in FLC chromatin: the expression of FLC transcripts is high before cold. Prior to winter (in autumn), high FLC levels are maintained through a set of regulators such as FRI (upregulates FLC expression), ATWDR5a and Paf1C (RNA polymerase associated factor 1 complex), which results in Histone 3 methylation at lysine 4 and 36 (H3K4me and H3K36me). During winter, the silencing of FLC is a gradual process regulated by the PHD-PRC2 complex, LHP1 and VAL1 recruitment at FLC, resulting in an increase of H3K27me repressive histone marks in FLC chromatin. Prolonged cold exposure also induced the expression of long noncoding RNA COOLAIR and COLDAIR. COLDAIR helps in PRC2 recruitment by interacting with CURLY LEAF (CLF). After return to warm temperatures, the mitotically-stable silencing of FLC is maintained by spreading H3K27me histone marks across the FLC chromatin to promote flowering in spring.

Fig. 4. Vernalization-induced flowering in temperate cereals (monocots) and Arabidopsis (eudicots). In temperate cereals (top panel), such as wheat and barley, prolonged cold induces VRN1 expression through epigenetic modifications in the VRN1 chromatin. VRN1 represses the expression of VRN2 that inhibit $V R N 3$ transcript. In spring, the long day photoperiod induces VRN3 expression and VRN1 expression remains high and accelerates flowering. VRN1 can also induce FPF1-like genes by inhibiting the expression of ODDSOC2 and therefore promoting flowering. In Arabidopsis (bottom panel), vernalization induced epigenetic silencing of FLC mediated through PRC2 and long non-coding RNAs COLDAIR and COOLAIR. FLC inhibits the expression of the floral integrator genes such as FD, FT and SOC1. Activation of these floral integrator genes promotes flowering in spring. 
Table 1: Different FLC homologs in monocots.

\begin{tabular}{|c|c|c|c|}
\hline S. No. & FLC homologs & Description and function & Reference \\
\hline 1. & $\begin{array}{l}\text { BdODDSOC2 } \\
\text { (Brachypodium) }\end{array}$ & $\begin{array}{l}\text { Downregulated during winter and a } \\
\text { repressor of flowering. Potential predictor of } \\
\text { vernalization requirement. }\end{array}$ & $\begin{array}{l}\text { Ruelens et al., } 2013 \\
\text { Sharma et al., } 2017\end{array}$ \\
\hline 2. & $\begin{array}{l}\text { BdODDSOC1 } \\
\text { (Brachypodium) }\end{array}$ & $\begin{array}{l}\text { Expression remains unchanged during } \\
\text { vernalization. }\end{array}$ & Ruelens et al., 2013 \\
\hline 3. & $\begin{array}{l}\text { BdMADS37 } \\
\text { (Brachypodium) }\end{array}$ & Downregulated during vernalization. & Ruelens et al., 2013 \\
\hline 4. & $\begin{array}{l}\text { TaAGL33 } \\
\text { (Wheat) }\end{array}$ & $\begin{array}{l}\text { Expression decreases upon prolonged cold } \\
\text { exposure. Expression levels before cold can } \\
\text { predict the vernalization requirement. }\end{array}$ & $\begin{array}{l}\text { Winfeild et al, } 2009 \\
\text { Sharma et al., } 2017\end{array}$ \\
\hline 5. & $\begin{array}{l}\text { TaAGL22 } \\
\text { (Wheat) }\end{array}$ & Downregulated during vernalization. & Sharma et al., 2017 \\
\hline 6. & $\begin{array}{l}\text { HvODDSOC2 } \\
\text { (Barley) }\end{array}$ & $\begin{array}{l}\text { Downregulated during vernalization and a } \\
\text { repressor of flowering. }\end{array}$ & $\begin{array}{l}\text { Greenup et al., } 2010 \\
\text { Ruelens et al., } 2013 \\
\text { Monteagudo et al., } \\
2019\end{array}$ \\
\hline
\end{tabular}



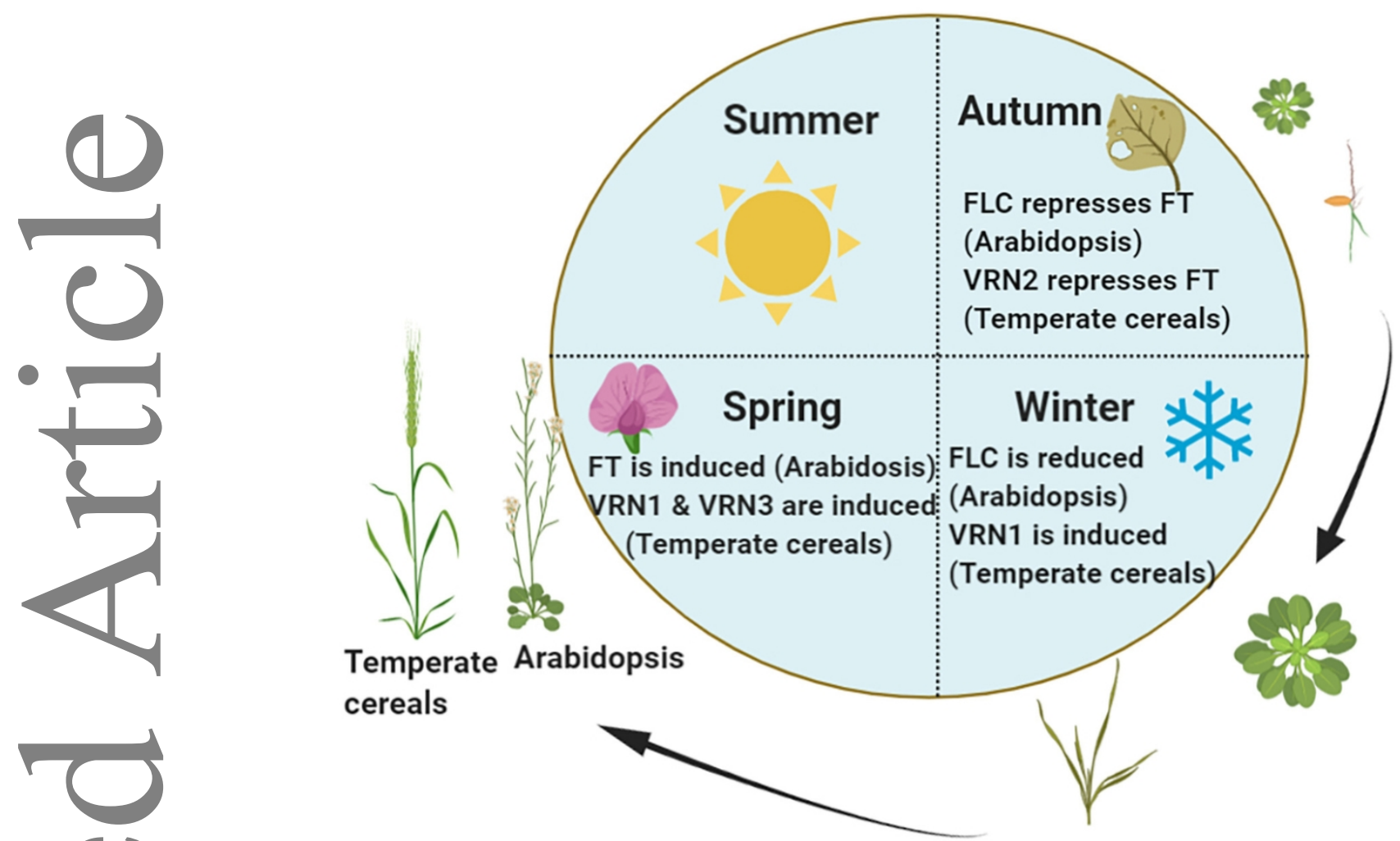

$99 \times 80 \mathrm{~mm}(300 \times 300 \mathrm{DPI})$ 

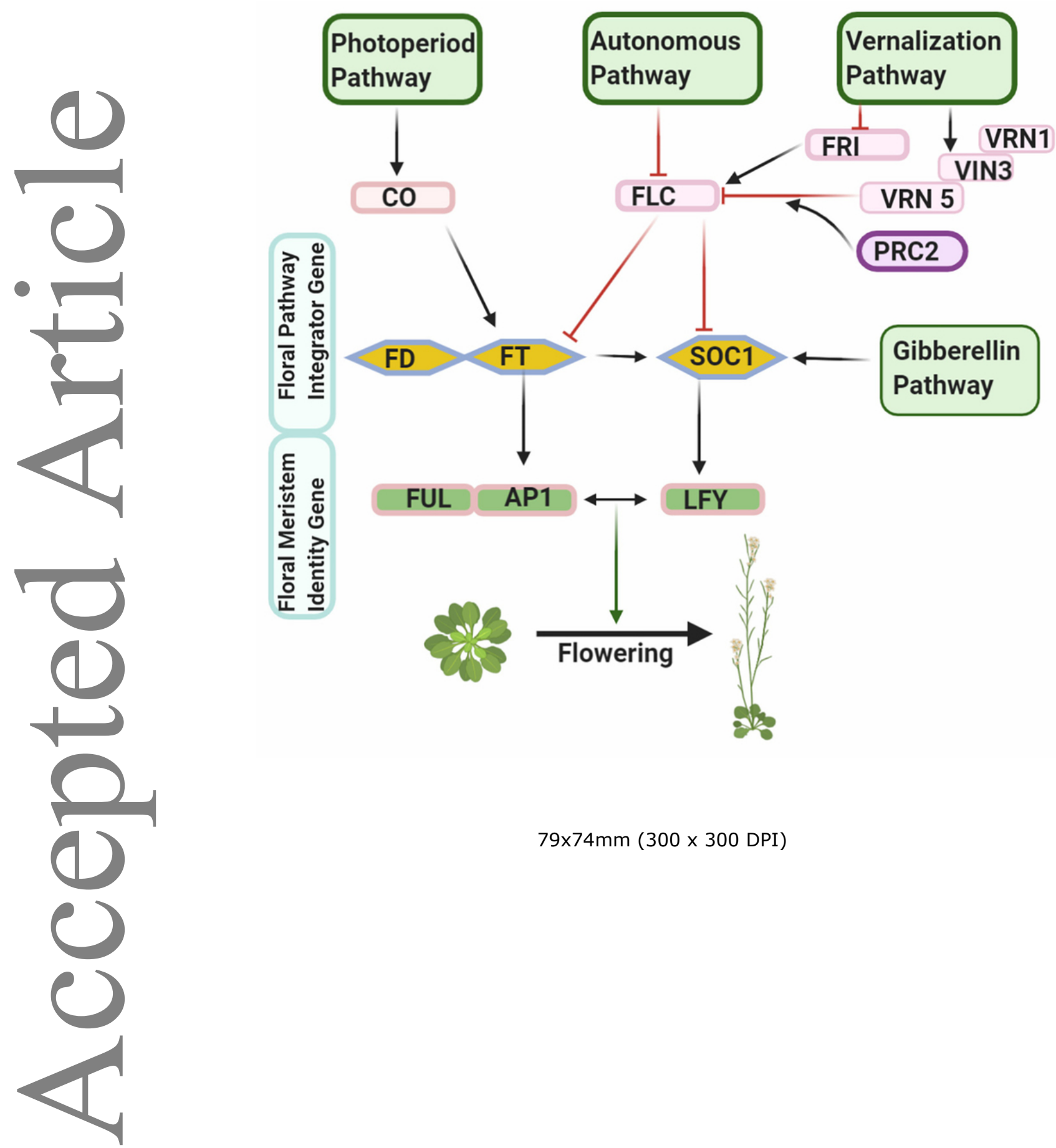

This article is protected by copyright. All rights reserved. 

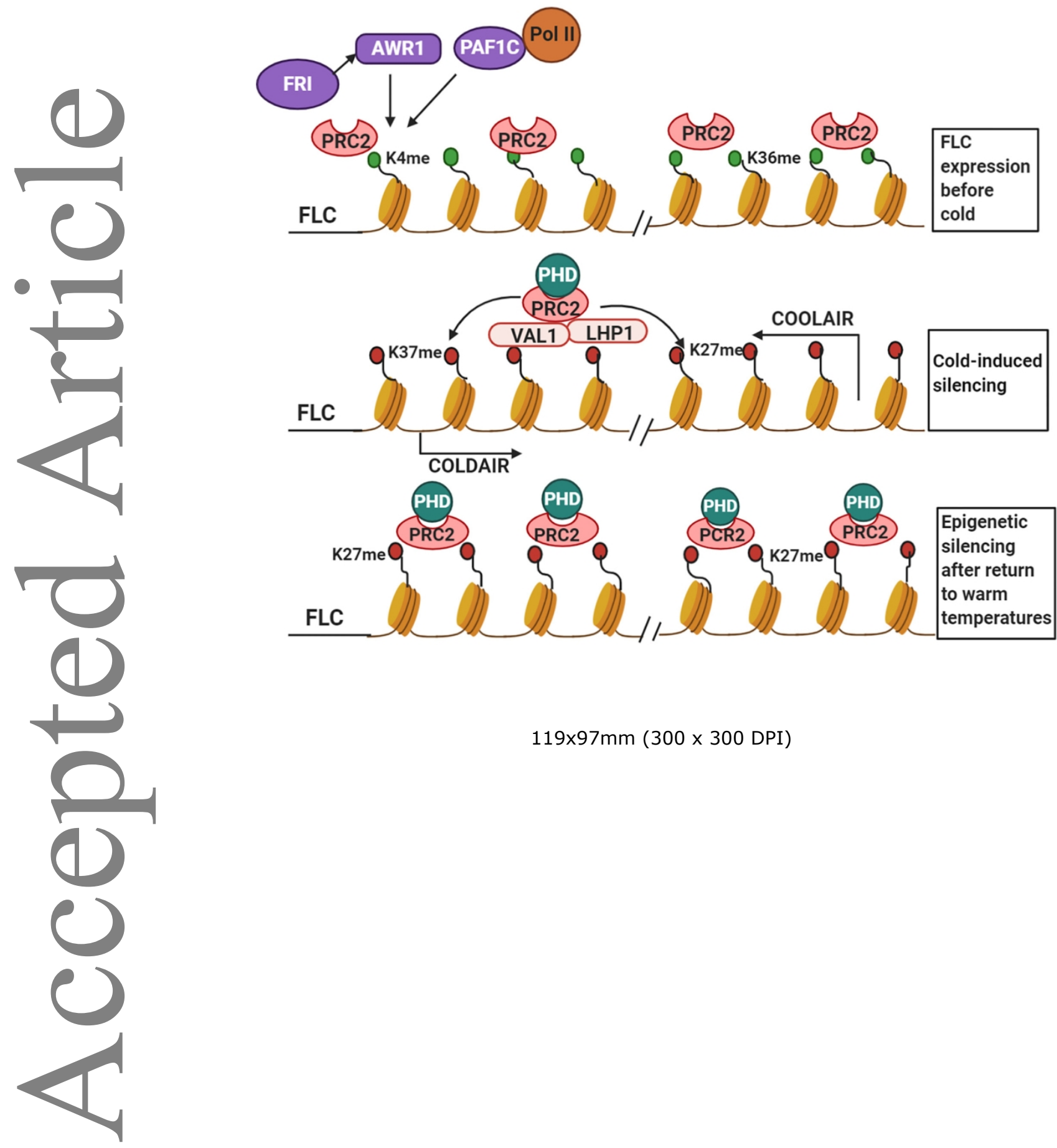

$119 \times 97 \mathrm{~mm}(300 \times 300 \mathrm{DPI})$ 

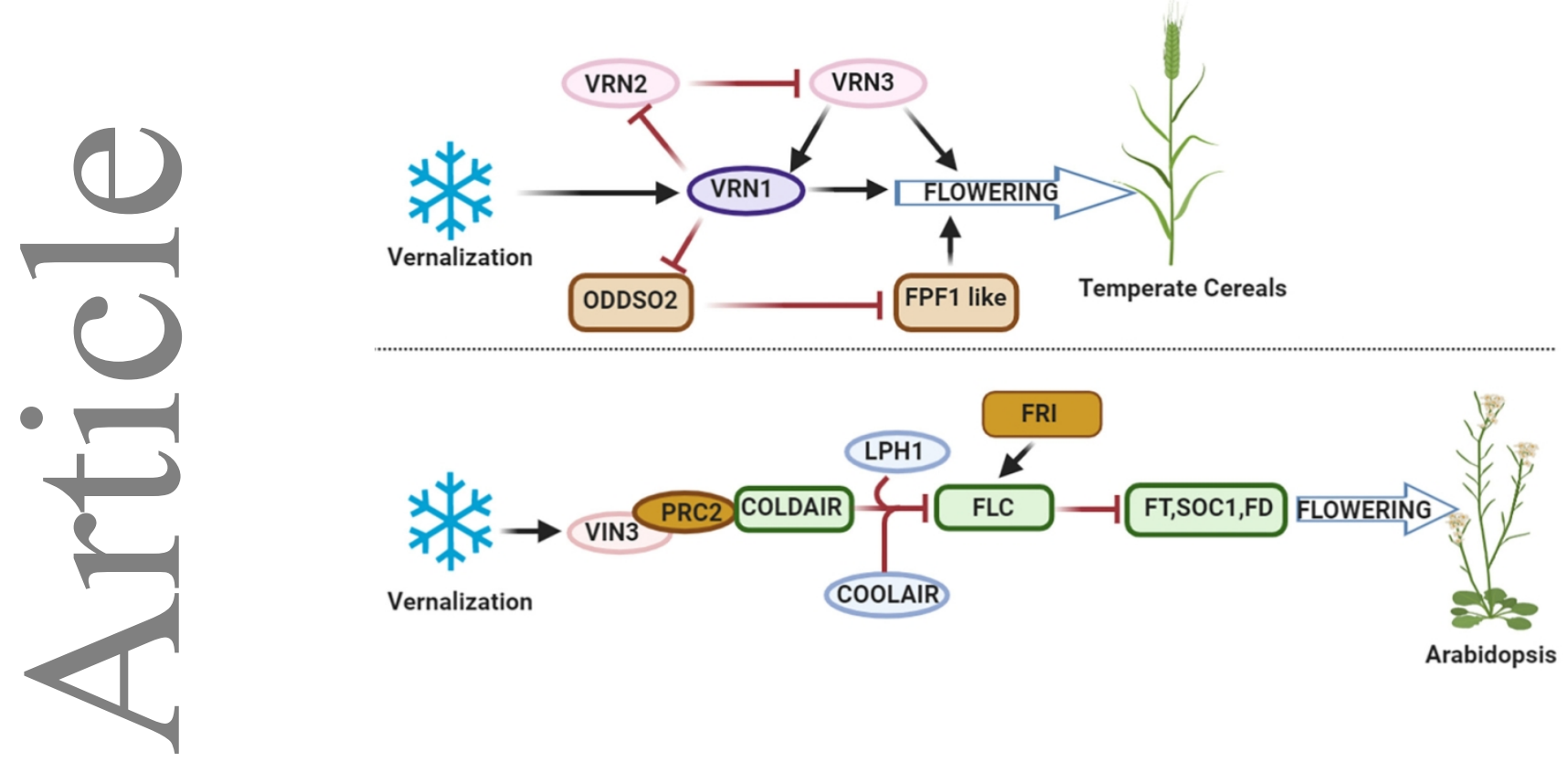

$119 \times 70 \mathrm{~mm}(300 \times 300 \mathrm{DPI})$

This article is protected by copyright. All rights reserved. 